\title{
The Status of Contaminants in Bald Eagles and Wildland Firefighters in the Teton Ecosystem
}

\author{
Authors \\ George Montopoli; Hank Harlow; W. R. Smith, MD; A. J. Wheeler, MD; Andy Byerly; and Michelle \\ Montopoli
}




\title{
The Status of Contaminants in BALd EAgles AND WILDLAND FIREFIGHTERS IN THE TETON ECOSYSTEM
}

\author{
George Montopoli $\downarrow$ Mathmatics Department $\downarrow$ Western ARizona College \\ YUMA \\ HANK HARLOW $\downarrow$ DEPARTMENT OF ZOOLOGY \& PHYSIOLOGY $\uparrow$ UNIVERSITY OF WYOMING \\ LARAMIE \\ W. R. SMITH, MD EMT-P $\downarrow$ ST. JOHN'S HOSPITAL $\downarrow$ JACKSON \\ A.J. WHEELER, MD $\downarrow$ ST. JOHN'S HOSPITAL $\downarrow$ JACKSON \\ ANDY BYERLY $\downarrow$ ST. JOHN'S HOSPITAL $\downarrow$ JACKSON \\ Michelle Montopoli $\downarrow$ University of ARIZONA MedicAl SCHOOL $\downarrow$ PhOENIX
}

\begin{abstract}
$\downarrow$ Abstract
Advancing global climate change and associated desiccation of temperate and boreal forests, exacerbated by extensive clear-cutting, may increase poisoning of aquatic ecosystems with high levels of contaminants, especially $\mathrm{Hg}$. We report on contaminants identified in nestling bald eagles and wildland firefighters of the Teton Ecosystem (Grand Teton National Park (GTNP) and the Snake River Unit (SRU), Wyoming) during summers of 2006, 2007 and 2008. In bald eagles, we focus primarily on mercury $(\mathrm{Hg})$, lead $(\mathrm{Pb})$, and selenium (Se) because each was detected in all nestlings during all summers at moderate levels. In wildland firefighters, we report primarily on $\mathrm{Hg}$ due to potential contamination from $\mathrm{Hg}$ when fighting fires and ingesting smoke and particulates produced by those fires.

We feel that studying $\mathrm{Hg}$ both in the eagles and humans simultaneously is a better indicator of the general health of the environment than studying them separately. Both humans and bald eagles occupy top tiers on the food web, and intricately reflect the status of the environment.
\end{abstract}

Results of the bald eagle analyses showed trends indicating increases in $\mathrm{Hg}$ and $\mathrm{Pb}$ from 2006 to 2007, and decreases from 2007 to 2008 . Selenium essentially remained constant from 2006 to 2007 and increased from 2007 to 2008. In wildland firefighters, $\mathrm{Hg}$ appears to be elevated in those firefighters who are exposed to significant levels of smoke and particulates, both in 2007 and 2008. Conjectures about firefighters, however, are not statistically significant due to small sample sizes and logistical problems.

Encouraging trends in bald eagle contaminant levels from 2007 to 2008 suggest reduction (or stabilization) of contaminant concentrations in the Teton Ecosystem. We also encourage the continued elimination of $\mathrm{Pb}$ attributable to humans (lead ammunition, lead shot, etc.) from the Teton Ecosystem. We encourage periodic monitoring of contaminants in the Teton Ecosystem, minimally at five-year intervals (Harmata 1996), unless unexpected events mandate more immediate monitoring. In wildland firefighters, we suggest a well-designed, comprehensive research study for summer 2009, to immediately address future ecological issues that are emerging due to climate change. 


\section{INTRODUCTION}

In the late 1980s, toxic elements and organochlorine pesticides were analyzed in blood \& sera of bald eagles (Haliaeetus leucocephalus) captured along the Snake River in northwestern Wyoming (Harmata and Oakleaf 1992). From $1985-1992,35 \%$ of bald eagles tested (total number $=146$ ) had detectable levels of $\mathrm{Pb}$, $91.4 \%$ had detectable levels of $\mathrm{Hg}$, and $100 \%$ had detectable levels of Se. At that time, survival and productivity of eagles did not appear affected. However, contaminant induced mortality was recorded in several eagles. Despite recommendations to monitor contaminants in nestling bald eagles at 5-year intervals (Harmata 1996), no follow-up analyses were conducted until summer 2006, after several bald eagles with $\mathrm{Hg}$ levels above the toxic threshold $(\geq 0.4 \mathrm{ppm}$ wet weight, Burgess et al. 2005) were submitted to the Montana Raptor Conservation Center (MRCC), a raptor rehabilitation and education organization in Bozeman, Montana.

Since December 2005, approximately 15 bald eagles and one golden eagle (Aquila chrysaetos) were submitted for treatment to MRCC. Analysis revealed that eagles contained toxic levels of $\mathrm{Hg}$ in their blood. Six died, one was released, and the rest remain in treatment but most likely will not be releasable. Symptoms of $\mathrm{Hg}$ toxicity were expressed by at least three other eagles submitted since October 2005, but their blood was not analyzed specifically for this metal. We suspect that $\mathrm{Hg}$ poisoning may have emerged prior to December 2005, but was not diagnosed (Harmata 2006).

Since the summer of 2006, we have investigated contaminants in nestling, wintering and migrant bald eagles in southwestern Montana and northwestern Wyoming. Here, we report on contaminants identified in nestling bald eagles of the Teton Ecosystem during summers of 2006, 2007, and 2007.

In late May 2007, while discussing the issue of $\mathrm{Hg}$ poisoning in bald eagles, we theorized that, if forest fires are the source of $\mathrm{Hg}$ contamination in the bald eagles, the contaminant could also manifest itself in other species, most notably wildland firefighters who occupy the immediate environment while combating forest fires. Exposure of firefighters to Hg may occur: 1) after its release into the atmosphere as a result of combustion of mercury-laden tree bark and other organic plants; and, 2) while firefighters inhale particulates resulting from activities such as digging fire line in unburned areas, especially peat bogs where microorganisms methylized the inorganic mercurial ion under riparian conditions.
During summer 2007, we therefore initiated a preliminary study to investigate if $\mathrm{Hg}$ accumulated at toxic levels in wildland firefighters who were exposed to smoke and other particulates while fighting fires in the western United States. During summer 2008, we continued monitoring $\mathrm{Hg}$ in the wildland firefighters. Here, we report on contaminants identified in wildland firefighters of the Teton Ecosystem during summers 2007 and 2008.

We feel that studying $\mathrm{Hg}$ both in the eagles and humans simultaneously is a better indicator of the general health of the environment than studying them separately.

\section{METHODS}

\section{Bald Eagles:}

Sampling was conducted at nest sites in the Teton Ecosystem (Table 1) during summers 2006, 2007, and 2008, along both lentic (Jackson Lake and Lower Slide Lake) and lotic systems (Snake River corridor from the Jackson Lake dam to the Elbow south of Hoback Junction).

\begin{tabular}{|l|l|l|}
\hline 2006 & $\mathbf{2 0 0 7}$ & $\mathbf{2 0 0 8}$ \\
\hline 4LazyF Ranch (2) & 4LazyF Ranch (3) & 4LazyF Ranch (2) \\
\hline & & Crane Creek Ranch (3) \\
\hline Elbow (1) & Elbow (2) & \\
\hline & & Ford's South (1) \\
\hline & Hoback Junction (1) & Hoback Junction (1) \\
\hline Lower Slide Lake \\
(1) & Lower Slide Lake (2) & Lower Slide Lake (1) \\
\hline Moose (2) & Moose (1) & Moose (2) \\
\hline & Oxbow Bend (1) & \\
\hline Refuge (2) & Refuge (1) & \\
\hline & Spaulding Bay (2) & \\
\hline $\begin{array}{l}\text { Triangle X Ranch } \\
(2)\end{array}$ & Triangle X Ranch (2) & \\
\hline
\end{tabular}

Table 1. Bald eagle nest sites sampled in the Teton ecosystem, 2006-2008. Number of nestlings at each nest site is given in parentheses.

In this study, we focus on $\mathrm{Hg}, \mathrm{Pb}$, and Se because they occurred in all nestlings during all summers at moderate levels and, due to their persistence in the environment, are of significant concern in the Teton Ecosystem. In addition, we tested six other soluble trace elements - antimony (Sb), arsenic (As), cadmium (Cd), chromium (Cr), nickel (Ni), thallium ( $\mathrm{Tl}$ ), 
and vanadium (V) - from 2006 to 2008, and DDE (organochlorine metabolite of DDT) in eight nestlings in 2007. Blood samples were analyzed at Michigan State University, Veterinary Medical Center, Diagnostic Center for Population and Animal Health, Clinical Pathology Laboratory (DCPAH), A215, East Lansing, MI 48824-1314.

We will present comprehensive information where appropriate, but we will mainly compare average occurrence of $\mathrm{Hg}, \mathrm{Pb}$, and Se over the three summers and examine any trends graphically. For more formal, comprehensive results and discussions, we refer you to last year's report, Monitoring of Contaminants in Nestling Bald Eagles of Grand Teton National Park (Montopoli et al. 2008).

\section{Wildland Firefighters:}

During summer 2007, in a preliminary, feasibility study, we analyzed blood for $\mathrm{Hg}, \mathrm{Pb}$ and three other soluble metals [cadmium $(\mathrm{Cd})$, cobalt $(\mathrm{Co})$, and Thallium (Tl)]. We measured contaminant levels for 12 subjects, and repeated blood draws for four of these subjects. For comprehensive results and discussions, we refer you to last year's report, Monitoring of Mercury in Wildland Firefighters (Montopoli et al. 2008).

During summer 2008, we continued the study, and expanded it to include a control group. We tested only for blood levels of $\mathrm{Hg}$ and $\mathrm{Pb}$. The proposed design involved the collection and analysis of $10 \mathrm{ml}$ blood samples from an exposure group and a control group. The control group consisted of 26 fulltime employees (seasonal or permanent) of Grand Teton National Park. The exposure group consisted of 19 wildland firefighters from the Teton Ecosystem who were exposed to substantial smoke and particulates from wildland fires.

We intended to take two blood draws per subject (pre- and post-contaminant exposure) and analyze the results using a related-samples t-test based on the repeated-measures design at a level of significance of 0.05 . A power analysis based on the difference score (post-Hg level minus pre- $\mathrm{Hg}$ level) allowed the detection of a medium effect due to $\mathrm{Hg}$ (Cohen's $\mathrm{d}=0.5$, alpha $=$ 0.05 and power $=0.8$; Cohen 1988). All Hg-panels were analyzed using a lab certified for the detection of $\mathrm{Hg}$ (St. John's Medical Center, P.O. Box 428 Jackson, WY $83001)$.

Participants also answered a brief questionnaire containing questions about demographics, prior $\mathrm{Hg}$ exposure, immediate exposure to smoke and particulates, and contact information. We obtained substantial assistance and support from the University of Washington's Medical School in procuring an Institutional Review Board (IRB) approval in both 2007 and 2008 .

Despite substantial shortcomings and limitations encountered during our research, we will present and discuss significant results from summer 2007 and 2008.

\section{$\uparrow \quad$ Results}

\section{Bald Eagles:}

Results from blood analyses taken from bald eagle nestlings during summer 2008 are summarized in Table 2 below.

The main purpose of this study involved the investigation of the occurrence of $\mathrm{Hg}, \mathrm{Pb}$, and $\mathrm{Se}$ in nestlings within the Teton Ecosystem over the course of the three summers. Table 3 summarizes levels of these environmental contaminants by year

\section{Wildland Firefighters:}

The exposure group consisted of 19 subjects. Of those 19 subjects, only six subjects completed both blood draws. Table 4 summarizes the results. 


\begin{tabular}{|l|l|l|l|l|l|l|l|l|l|l|l|}
\hline Nest Site & $\mathrm{Sb}$ & $\mathrm{As}$ & $\mathrm{Be}$ & $\mathrm{Cd}$ & $\mathrm{Cr}$ & $\mathrm{Pb}$ & $\mathrm{Hg}$ & $\mathrm{Ni}$ & $\mathrm{Se}$ & $\mathrm{Tl}$ & $\mathrm{V}$ \\
\hline Hoback Junction & $<25$ & $<5$ & $<25$ & $<5$ & $<25$ & 21 & 275 & $<25$ & 1654 & $<5$ & $<25$ \\
\hline Crane Ck Ranch & $<25$ & 49 & $<25$ & 6 & $<25$ & 26 & 131 & $<25$ & 1800 & $<5$ & $<25$ \\
\hline Crane Ck Ranch & $<25$ & 31 & $<25$ & 20 & $<25$ & 50 & 112 & 45 & 1636 & $<5$ & $<25$ \\
\hline Crane Ck Ranch & $<25$ & 34 & $<25$ & 10 & $<25$ & 25 & 138 & $<25$ & 1448 & $<5$ & $<25$ \\
\hline Ford's South & $<25$ & $<5$ & $<25$ & 7 & $<25$ & 20 & 312 & $<25$ & 2325 & $<5$ & $<25$ \\
\hline Moose Nest & $<25$ & $<5$ & $<25$ & 7 & $<25$ & 19 & 83 & $<25$ & 1024 & $<5$ & $<25$ \\
\hline Moose Nest & $<25$ & $<5$ & $<25$ & 10 & $<25$ & 32 & 162 & 32 & 1504 & $<5$ & $<25$ \\
\hline 4LazyF Ranch & $<25$ & $<5$ & $<25$ & 6 & $<25$ & 21 & 270 & $<25$ & 3363 & $<5$ & $<25$ \\
\hline 4LazyF Ranch & $<25$ & $<5$ & $<25$ & 7 & $<25$ & 21 & 261 & $<25$ & 3183 & $<5$ & $<25$ \\
\hline Lower Slide Lake & $<25$ & $<5$ & $<25$ & 7 & $<25$ & 21 & 310 & $<25$ & 1191 & $<5$ & $<25$ \\
\hline
\end{tabular}

Table 2. Soluble trace elements (ppb wet wt.) detected in blood of nestling bald eagles.

\begin{tabular}{|c|c|c|c|c|c|c|c|c|c|}
\hline \multirow[b]{2}{*}{ Nest Site } & \multicolumn{3}{|c|}{$\mathrm{Hg}$} & \multicolumn{3}{|c|}{$\mathrm{Pb}$} & \multicolumn{3}{|c|}{$\mathrm{Se}$} \\
\hline & 2006 & 2007 & 2008 & 2006 & 2007 & 2008 & 2006 & 2007 & 2008 \\
\hline \multirow{3}{*}{ 4LazyF Ranch } & 0.150 & 0.204 & 0.270 & 0.003 & 0.019 & 0.021 & 0.755 & 1.415 & 3.363 \\
\hline & 0.261 & 0.210 & 0.261 & 0.003 & 0.028 & 0.021 & 0.823 & 1.758 & 3.183 \\
\hline & & 0.563 & & & 0.089 & & & 1.285 & \\
\hline \multirow{3}{*}{$\begin{array}{c}\text { Crane Creek } \\
\text { Ranch }\end{array}$} & & & 0.131 & & & 0.026 & & & 1.8 \\
\hline & & & 0.112 & & & 0.05 & & & 1.636 \\
\hline & & & 0.138 & & & 0.025 & & & 1.448 \\
\hline \multirow[t]{2}{*}{ Elbow Nest } & 0.614 & 0.697 & & 0.004 & 0.011 & & 1.477 & 1.316 & \\
\hline & & 0.742 & & & 0.011 & & & 1.599 & \\
\hline Ford's South & & & 0.312 & & & 0.02 & & & 2.325 \\
\hline $\begin{array}{l}\text { Hoback } \\
\text { Junction }\end{array}$ & & 0.358 & 0.275 & & 0.014 & 0.021 & & 1.044 & 1.654 \\
\hline \multirow[t]{2}{*}{$\begin{array}{l}\text { Lower Slide } \\
\text { Lake }\end{array}$} & 0.975 & 0.539 & 0.310 & 0.006 & 0.011 & 0.021 & 1.191 & 0.980 & 1.191 \\
\hline & & 0.575 & & & 0.012 & & & 1.270 & \\
\hline \multirow[t]{2}{*}{ Moose Nest } & 0.096 & 0.230 & 0.083 & 0.008 & 0.012 & 0.019 & 0.505 & 1.896 & 1.024 \\
\hline & 0.291 & & 0.162 & 0.003 & & 0.032 & 0.619 & & 1.504 \\
\hline Oxbow Bend & & 0.797 & & & 0.193 & & & 1.783 & \\
\hline \multirow[t]{2}{*}{ Refuge Nest } & 0.115 & 0.146 & & 0.006 & 0.012 & & 3.498 & 2.722 & \\
\hline & 0.142 & & & 0.007 & & & 3.648 & & \\
\hline \multirow[t]{2}{*}{ Spaulding Bay } & & 0.360 & & & 0.021 & & & 0.549 & \\
\hline & & 0.367 & & & 0.166 & & & 0.574 & \\
\hline \multirow[t]{2}{*}{$\begin{array}{c}\text { Triangle X } \\
\text { Ranch }\end{array}$} & 0.212 & 0.342 & & 0.014 & 0.142 & & 0.542 & 1.019 & \\
\hline & 0.242 & 0.407 & & 0.005 & 0.120 & & 0.654 & 1.318 & \\
\hline $\begin{array}{c}\text { Geometric } \\
\text { Mean }\end{array}$ & 0.237 & 0.388 & 0.187 & 0.0052 & 0.0304 & 0.024 & 1.045 & 1.256 & 1.781 \\
\hline
\end{tabular}

Table 3. A comparison of $\mathrm{Hg}, \mathrm{Pb}$, and $\mathrm{Se}$ concentrations (ppm wet wt.) in nestling bald eagles by year and nest site. 


\begin{tabular}{|l|l|l|}
\hline Subject & Draw 1 & Draw 2 \\
\hline 1 & $<4$ & $<4$ \\
\hline 2 & $<4$ & $<4$ \\
\hline 3 & $<4$ & $<4$ \\
\hline 4 & $<4$ & $<4$ \\
\hline 5 & 6 & 7 \\
\hline 5 & 9 & 8 \\
\hline
\end{tabular}

Table 4. Summary of $\mathrm{Hg}(\mathrm{mcg} / \mathrm{dL})$ occurrence for subjects completing a pre- and post-blood draw in the exposure group

The control group consisted of 26 subjects. Of those 26 subjects, only 11 subjects completed both blood draws. Table 5 summarizes the results.

\begin{tabular}{|l|l|l|}
\hline Subject & Draw 1 & Draw 2 \\
\hline 1 & $<4$ & $<4$ \\
\hline 2 & $<4$ & $<4$ \\
\hline 3 & $<4$ & $<4$ \\
\hline 4 & $<4$ & $<4$ \\
\hline 5 & $<4$ & $<4$ \\
\hline 6 & $<4$ & $<4$ \\
\hline 7 & $<4$ & $<4$ \\
\hline 8 & $<4$ & $<4$ \\
\hline 9 & $<4$ & 6 \\
\hline 10 & 5 & $<4$ \\
\hline 11 & 6 & 7 \\
\hline
\end{tabular}

Table 5. Summary of $\mathrm{Hg}(\mathrm{mcg} / \mathrm{dL})$ occurrence for subjects completing a pre- and post-blood draw in the control group

Wildland firefighters were also tested for the presence of $\mathrm{Pb}$ in their blood, but results were unremarkable. Lead was encountered at non-detectable levels $(<3 \mathrm{mcg} / \mathrm{dL})$ in $94 \%$ of all blood analyses $(62$ total analyses), and never measured more than 4 $\mathrm{mcg} / \mathrm{dL}$ in the four cases where $\mathrm{Pb}$ level was detectable.

\section{DISCUSSION}

\section{Bald Eagles:}

Environmental contaminants in bald eagles are a persistent issue in Montana and Wyoming, especially in the Teton Ecosystem. Although blood analyses from nestling eagles surveyed during the summers of 2006, 2007 and 2008 suggest the riparian ecosystem supporting these eagles contains generally low levels of contaminants, several issues of concern emerged.

Examination of Table 1 indicates a high concentration of As in the three nestlings at the Crane
Creek Ranch nest site (geometric mean $=37.24 \mathrm{ppb}$ ), especially when compared to other nestlings $(<5 \mathrm{ppb})$. Possible causes include unintentional poisoning from rodent-control measures employed by local ranches, or some other point source contamination occurring in the nestlings' food source. Arsinecosis, or mortality of bald eagles directly attributable to As, has not been documented in WY. Levels of As in blood of eagles found here may be reflective of background levels, sensitivity of analysis, or both. One-hundred percent of Wyoming nestlings exhibit detectable levels of As and the contamination may be inconsequential. However, monitoring of bald eagles productivity in this area is suggested.

The geometric mean will be used when comparing trends from 2006 through 2008 for $\mathrm{Pb}, \mathrm{Hg}$, and Se concentrations. The geometric mean is more appropriate when data are presented as concentrations. Formal statistical analyses will not be performed on data because results from 2007 indicated limited statistical significance due to small sample sizes and violations of independence of observations (Montopoli et al. 2008). We feel that the overall trend demonstrated graphically best indicates the actual situation.

Figure 1 shows an $873 \%$ increase (almost nine-fold increase) in $\mathrm{Pb}$ levels in the blood of nestlings from 2006 to 2007 and a $55 \%$ decrease from 2007 to 2008.

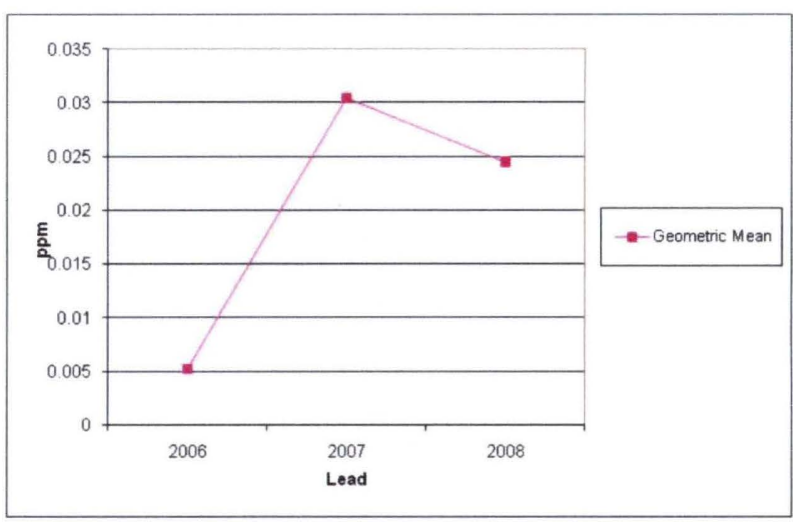

Figure 1. Geometric mean concentration of $\mathrm{Pb}$ in nestling Bald Eagles (2006-2008)

Because of limited data, we question whether the increase in $\mathrm{Pb}$ from summer 2006 to 2007, and decrease from summer 2007 to 2008 , is due to chance occurrence, or perhaps from some environmental contamination effect. We welcome the decrease in $\mathrm{Pb}$ from summer 2007 to 2008 , after such a sharp increase from summer 2006 to 2007. 
We continue to support the removal of any localized sources of $\mathrm{Pb}$ contamination from the proximity of any nest sites (for example, elk harvest where lead rifle bullets are allowed, or lead shot used in fishing). We support continued periodic monitoring of $\mathrm{Pb}$ contamination in the future (Craighead and Bedrosian 2008). Removal of $\mathrm{Pb}$ contamination attributable to humans from the general environment is our ultimate goal.

Figure 2 shows a $64 \%$ increase in $\mathrm{Hg}$ levels in the blood of nestlings from 2006 to 2007 and a $52 \%$ decrease from 2007 to 2008 . We welcome the decrease in $\mathrm{Hg}$ from summer 2007 to 2008, after the increase from summer 2006 to 2007. Summer 2008 experienced a relatively slow fire season when compared to summer 2007. We feel that the decrease in $\mathrm{Hg}$ may be due to this phenomenon.

Natural degassing of the earth's crust is the major source of environmental $\mathrm{Hg}$ worldwide (Heinz 1996) and coal-fired utilities are the largest single unregulated anthropogenic source of $\mathrm{Hg}$ emissions in the United States (USEPA 1997). However, recent data indicate wildfires are responsible for massive aerosols of $\mathrm{Hg}$ (Friedli et al. 2003) and could release 15 times more $\mathrm{Hg}$ into the air than every U.S. coal-fired power plant combined (Friedli et al. 2001). Biswas et al. (2003) indicated combustion of litter and green vegetation resulted in virtually complete release of $\mathrm{Hg}$ stored in fuel and forests in the Rocky Mountain region. Montana and Wyoming forests may contain large reservoirs of $\mathrm{Hg}$ deposited during the industrial age that can be released during fires, especially the mega-fires that we are currently experiencing in our environment.

Additionally, $\mathrm{Hg}$ concentrations in fish were related to ratio of the clear-cut (forest logging) size to lake area in Canadian boreal forests (Garcia and Carignan 2005), suggesting large scale logging operations contribute to $\mathrm{Hg}$ contamination of higher trophic-level piscivorous predators (Driscoll et al. 1994), which may bioaccumulate in higher trophic-level predators. Thus, a reduction in the extensive forest fires that we experienced prior to 2008 may explain the reduction in $\mathrm{Hg}$ contamination in 2008.

Figure 3 shows a $0.15 \%$ increase in Se levels in the blood of nestlings from 2006 to 2007 and a $40 \%$ increase from 2007 to 2008 . We welcome the increase in Se from summer 2007 to 2008 , after it essentially remained constant from summer 2006 to 2007.

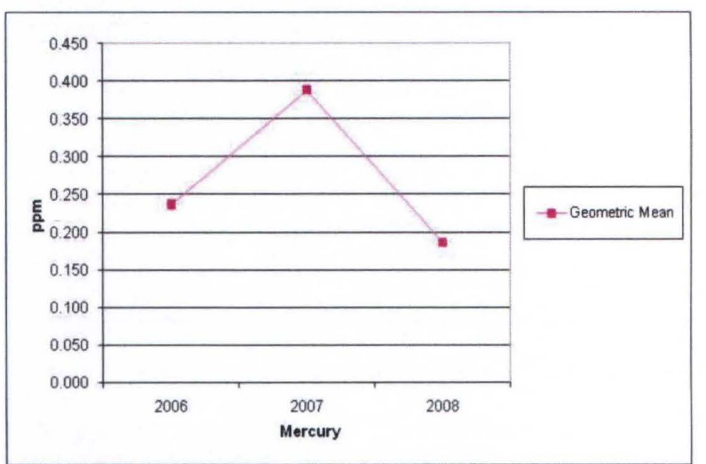

Figure 2. Geometric mean concentration of $\mathrm{Hg}$ in nestling Bald Eagles (2006-2008)

In a study involving ospreys, Odsjo et al. (2004) noted that a 1:1 molar ratio $(2.54 \mathrm{ppm} \mathrm{Se}: 1 \mathrm{ppm}$ $\mathrm{Hg}$ ) is considered efficacious for detoxifying Hg. From 2006 to 2007, the molar ratio (based on the geometric mean) in nestlings decreased from $11: 1$ to $8: 1$, and from 2007 to 2008 increased from 8:1 to 24:1. Because Se mitigates the toxic effect of $\mathrm{Hg}$, nestlings could succumb to $\mathrm{Hg}$ toxicity if $\mathrm{Hg}$ levels increased while $\mathrm{Se}$ levels decreased. Currently, the trend indicates a decrease in $\mathrm{Hg}$ and an increase in Se, and Se appears available to nestling bald eagles in sufficient quantities to mitigate any effects of $\mathrm{Hg}$ contamination.

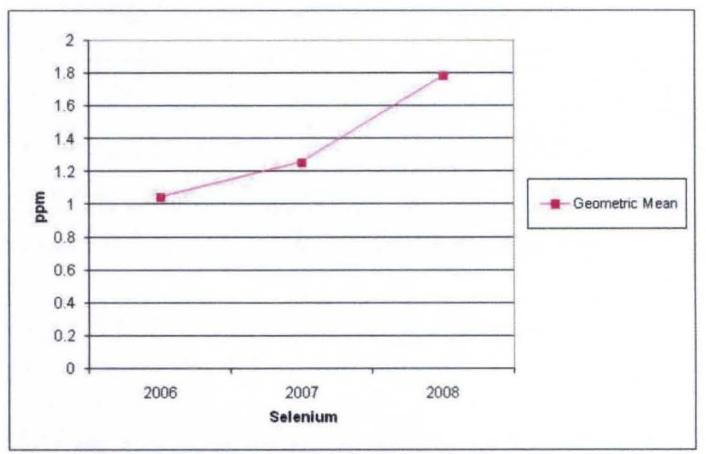

Figure 3. Geometric mean concentration of Se in nestling Bald Eagles (2006-2008)

All nests that we surveyed fall within a National Park or are within geographical jurisdictions that protect the environment from contaminants. Any increase in the levels of these contaminants is therefore not expected. Encouraging trends in bald eagle contaminant levels from 2007 to 2008 suggest reduction (or stabilization) of contaminants in the Teton Ecosystem. We encourage the continued elimination of lead attributable to humans (lead ammunition, lead shot, etc.) from the Teton Ecosystem. We encourage periodic monitoring of contaminants in the Teton Ecosystem, perhaps at five-year intervals, unless unexpected events mandate more immediate monitoring. 


\section{Wildland Firefighters:}

Unfortunately, we experienced limitations to our original designs for both summers because we were unable to sample enough individuals pre- and postexposure to smoke. We were also unable to accurately measure times of exposure to smoke and other information for all subjects, and many of the subjects did not experience the high levels of smoke and particulates the that we anticipated. These limitations were mostly due to logistical oversights and IRB approval prior to initiation of the fire season. Conclusions drawn from the limited study, especially the small sample, are tenuous at best. However, the following results merit discussion:

1) During 2007:

- Besides $\mathrm{Hg}$, blood analyses were performed for the presence of four other metals ( $\mathrm{Pb}, \mathrm{Cd}, \mathrm{Co}$, and $\mathrm{Tl})$. Levels of these metals, though not precisely reported $(<3.0$ $\mathrm{mcg} / \mathrm{dL},<0.5 \mathrm{mcg} / \mathrm{L},<1.0 \mathrm{mcg} / \mathrm{L}$, and $<1.0$ $\mathrm{mcg} / \mathrm{L}$, respectively, for all subjects), were well-below toxic thresholds and within normal range for all subjects.

- Three of the subjects had measurable $\mathrm{Hg}$ levels $(7 \mathrm{mcg} / \mathrm{L}, 7 \mathrm{mcg} / \mathrm{L}$, and $8 \mathrm{mcg} / \mathrm{L})$ that approached the limit of a non-toxic $\mathrm{Hg}$ concentration $(<10 \mathrm{mcg} / \mathrm{L})$. A fourth subject had a measurable level of $4 \mathrm{mcg} / \mathrm{L}$. All other subjects had levels designated by $<4 \mathrm{mcg} / \mathrm{L}$.

- For the four subjects with repeated blood draws, two demonstrated an increase in mercury levels over time ( $<4$ to $7 \mathrm{mcg} / \mathrm{L}$, and 5 to $8 \mathrm{mcg} / \mathrm{L}$ ), one showed no change over time ( $<4$ to $<4 \mathrm{mcg} / \mathrm{L})$, and one demonstrated a decrease in mercury levels over time (4 to $<4 \mathrm{mcg} / \mathrm{L}$ ).

2) During 2008:

- In both the exposure and control groups, $\mathrm{Pb}$ occurred at non-detectable levels in $94 \%$ of all blood tests (total analyses $=62$ ), and minimally detectable in the four remaining cases.

- In the exposure group, of the six participants with two draws, four showed levels of $<4 \mathrm{mcg} / \mathrm{L}$ for both draws, while two showed elevated levels of $\mathrm{Hg}$ for both draws $(6 \rightarrow 7$ and $9 \rightarrow 8 \mathrm{mcg} / \mathrm{L})$. Both of these participants were on the helitack crew, which suggest that $\mathrm{Hg}$ exposure may be related to smoke and particulate exposure. Unfortunately, background exposure information is incomplete.
○ In the exposure group, two other helitack members who only had one blood draw taken demonstrated high levels of $\mathrm{Hg}$ (9 and 5 $\mathrm{mcg} / \mathrm{L}$ ). Other members of the exposure group most likely experienced minimal smoke exposure. Two participants from nonfirefighting crews reported some exposure, but they only had one blood draw taken $(<4$ $\mathrm{mcg} / \mathrm{L}$ ).

- In the control group, of the 11 participants with two draws, two showed elevated levels of $\mathrm{Hg}(<4 \rightarrow 6$ and $6 \rightarrow 7$ $\mathrm{mcg} / \mathrm{L})$. All other subjects were $<4 \mathrm{mcg} / \mathrm{L}$ for both blood draws.

3) During 2007 and 2008, we recorded times of exposure to smoke and other information for all subjects. Data were incomplete and our sample was too small to investigate any statistical inference about the relationship between the duration of exposure to smoke and changes in blood $\mathrm{Hg}$ concentration.

Despite the limititations of our research during both 2007 and 2008, we encountered Hg at measureable levels in several subjects who were exposed to elevated levels of smoke and particulates as part of their work environment. Subjects who comprised the control group, and subjects in the treatment group who experienced little exposure to smoke or particulates, exhibited non-detectable to low levels of $\mathrm{Hg}$. No other soluble metals were measureable at detectable levels in almost all of the subjects. Consequently, we feel this research merits further investigation with the following modifications:

- The study should be expanded to a significantly larger sample (at least 50, contingent on funding) of wildland firefighters in the Teton Ecosystem who are exposed to substantially elevated levels of smoke and particulates. A majority of the firefighters should belong to hot-shot crews that are extensively exposed to fire contaminants (smoke and particulates) over the duration of the summer.

- A similarly-sized control group consisting of volunteers who spend a significant amount of time in the outdoors free of smoke should be used as a comparative sample.

- It is essential that $\mathrm{Hg}$ levels in each subject are analyzed a minimum of two times during the firefighting season, optimallyprior to commencement of the fire season; and ii) well into, or at the end of, the fire season 
after considerable exposure to smoke and fire particulates.

- Time of exposure to smoke particulates by firefighters should be estimated accurately.

- If the budget permits, hair samples from the back of the neck (which are fast growing) could be easily harvested to determine if mercury levels are due to chronic or acute exposure.

\section{ACKNOWLEDGEMENTS}

We wish to express our deepest appreciation to the following organizations and individuals for their collaboration in our research project: Dr. Alan Harmata, Montana State University; Grand Teton National Park (especially Andy Fisher, Jim Springer, Renny Jackson, Ed Visnovske, Chris Harder, Scott Guenther, and Cindy O'Neill); Wyoming Game and Fish Department (especially Bob Oakleaf and Susan Patla); University of Wyoming-National Park Service Research Station (especially Celeste Havener), and Arizona Western College (especially Mary Schaal).

\section{Literature Cited}

Biswas, A., J.D.Blum and G.J. Keeler. 2003. Forest fire effects on mercury and other trace metal concentrations in a Rocky Mountain forest ecosystem. EOS Transactions of American Geophysical Union 84 (46). Fall Meeting. Supplemental. Abstract \#B32C-05.

Burgess, N.M, D.C. Evers and J.D. Kaplan. 2005. Mercury and other contaminants in common loons breeding in Atlantic Canada. Ecotoxicology 14:241-252.

Craighead, D. and B. Bedrosian, 2008. Blood levels of common ravens with access to big game offal. Journal of Wildlife Management. In press.

Driscoll, C.T., C. Yan, C.L. Schofield, R. Munson and J. Holsapple. 1994.The mercury cycle and fish in the Adirondack lakes. Environmental Science and Technology 28:136A-143A.

Friedli, H.R., L.F. Radke and J.Y. Lu. 2001. Mercury in Smoke from Biomass Fires. Geophysical Research Letters 28:3223-3226.

Friedli, H.R., L.F. Radke, J.Y. Lu, C.M. Banic, W.R. Leaitch and J.I. MacPherson. 2003. Mercury emissions from burning of biomass from temperate North American forests: laboratory and airborne measurements. Atmospheric Environment 37:253-267

Garcia, E. and R. Carignan. 2005. Mercury concentrations in fish from forest harvesting and fire-impacted Canadian boreal lakes compared using stable isotopes of nitrogen. Environmental Toxicology and Chemistry 24:685-693.

Harmata, A.R. and B. Oakleaf. 1992. Bald Eagles of the Greater Yellowstone Ecosystem: An ecological study with emphasis on the Snake River, Wyoming. Wyoming Game \& Fish Dept., Lander. 368 pp.

Harmata, A.R. 1996. Bald eagle management plan for Greater Yellowstone: 1995 Update. Greater Yellowstone Bald Eagle Working Group. Wyoming Game \& Fish Dept., Lander, Wyoming. $47 \mathrm{pp}$.

Harmata, A.R. 2006. Monitoring mercury and other contaminants in bald eagles in southwestern Montana \& northwestern Wyoming. Interim Report 30 November 2006

Heinz, G.H. 1996. Mercury poisoning in wildlife. Pgs. 118-127. In: Noninfectious diseases of wildlife. A. Fair-brother, L.N. Locke, and G.N. Hoff (eds.). Iowa State University Press, Ames, Iowa.

Montopoli, G., H. Harlow, A. Byerly, S. Wolff and S. Patla. 2008. Monitoring of contaminants in nestling Bald Eagles of Grand Teton National Park. University of Wyoming - National Park Service Research Center 31st Annual Report 2008

Montopoli, G., W. Smith, M. Menolascino, A.J. Wheeler and A. Byerly. 2008. Monitoring of mercury in wildland firefighters. University of Wyoming National Park Service Research Center 31st Annual Report 2008

Odsjo, T., A. Roos and A.G. Johnels. 2004. The tail feathers of osprey nestlings (Pandion haliaetus $L$.) as indicators of change in mercury load in the environment of southern Sweden (1969-1998): a case study with a note on the simultaneous intake of selenium. Ambio 33:133-137.

U.S. Environmental Protection Agency. 1997. Mercury Study Report to Congress. USEPA, Washington, D.C. 8 Vol. http://www.epa.gov/mercury/ report.htm 